\title{
ALBERT CAMUS Y LA FILOSOFÍA DEL LÍMITE (LECTURA CASI NIETZSCHEANA DE EL HOMBRE REBELDE)
}

Enrique CEJUDO BORREGA

Profesor del IES $n .{ }^{\circ} 1$ de Cheste (Valencia)

«Durante unas horas podemos ser infelices a la manera de los hombres libres».

Primo Levi: Si esto es un hombre

Resumen: El presente articulo tiene como objetivo la aproximación a un autor, $y$ en concreto a uno de sus textos, que no suele aparecer en los manuales de filosofia, ni siquiera en los libros monográficos que hablan del existencialismo. Hablamos de Albert Camus (1913-1960) y de su obra El hombre rebelde (1951).

\section{Introducción}

Se ha mirado durante demasiado tiempo con recelo a otros ámbitos próximos a la filosofía: el arte, la ciencia, la religión... En nombre de no se sabe muy bien qué purezas o especificidades se ha ignorado todo lo que la filosofía puede y debe aprender de ellas. Desde posiciones ciertamente arrogantes, la filosofía se ha otorgado el derecho a reflexionar sobre todo. Se ha autodenominado disciplina o ciencia de segundo grado, reflexión crítica acerca de cualquier ámbito de cualquier realidad, etc. Demasiadas pretensiones tal vez, que debieran ser contaminadas por saberes más mestizos e intercomunicados.

Albert Camus es sobre todo conocido por su teatro y sus novelas: El extranjero, La peste, Calígula, La caida, Los justos, etc. Pero, además, contamos con otros textos menos narrativos, especialmente el ya referido $E l$ hombre rebelde y El mito 
de Sisifo, además de una especie de autobiografía novelada sin terminar (se encontró entre sus papeles en el lugar del accidente en que perdió la vida), $E l$ primer hombre, y muchos otros más: El revés y el derecho, El verano, El exilio y el reino, etc. Quien lea cualquiera de ellos se dará cuenta de que está ante literatura filosófica.

Se le suele encuadrar dentro de las corrientes literarias y filosóficas llamadas existencialistas o vitalistas. Tal vez el mayor campo de significado que abarca esta última hiciera a Camus sentirse más a gusto bajo esa denominación; desde luego no lo estaba con el calificativo de existencialista, aunque pudiera admitirse con amplio criterio. Sería vitalista toda obra que refleje problemas vivenciales que comprometan al ser humano. Estas obras no cuentan exactamente una historia particular, sino que contienen un problema humano, y no sólo el problema de un humano.

A Camus se le asocia a menudo - y con bastante imprecisión-con JeanPaul Sartre ${ }^{1}$, y no tan a menudo con Friedrich Nietzsche. Sin embargo, es sobre todo el autor alemán el que le cimienta y nutre. Los dos, Camus y Nietzsche, han sido malentendidos hasta la náusea, y la sombra de la palabra nihilismo ha caído sobre ellos, convirtiéndolos en filósofos del no, en pura negatividad, en destructores tan sólo, por lo que han terminado por disolverse en una serie de fragmentos mal leídos y peor entendidos. Más en el caso de Nietzsche, sin duda; sobre Camus más bien ha caído la semántica opaca pero biensonante del existencialismo, empapándolo de uniformidad sartreana. Lectores de tapas y tópicos han creado pensadores inexistentes.

El propio Camus pedía para Nietzsche, así como para Marx, un reconocimiento histórico (¿una relectura?) que los crímenes cometidos bajo el paraguas de su supuesto pensamiento habían prohibido. A comienzos del siglo XXI todo parece más fácil, pero hacerlo en 1951, apenas terminada la Segunda Guerra Mundial, con las heridas aún abiertas y el recuerdo doloroso del régimen nazi y su lenguaje usurpador (resonaban todavía expresiones como superhombre, bestia rubia, moral de señores, etc.), no es poco atrevimiento. Claro que Camus, como Nietzsche, no está servilmente comprometido con partido

1 Véase su historia de amistad/colaboración y posterior alejamiento intelectual y personal en cualquier biografía, por ejemplo en la de Herbert LOTTMAN: Albert Camus, ed. Taurus, Madrid, 1994, concretamente los capítulos titulados "El hombre rebelde" y "Sartre contra Camus", pp. 511-45. El detonante (¿excusa?) de su ruptura fue, precisamente, la publicación de El hombre rebelde. 
político alguno ${ }^{2}$. Su compromiso sólo es con la vida, con la libertad, con el pathos inevitable, gozoso y doloroso, en que consiste la existencia.

Nietzsche parece dictar a veces párrafos enteros de El hombre rebelde. Incluso le es dedicado un magnífico capítulo de apenas 16 páginas, «Nietzsche y el nihilismo", esencial para comprender la vinculación con el pensador alemán y para conocer el significado genuino de la filosofía de éste (por cierto, dicho capítulo es absolutamente ninguneado por la hermenéutica nietzscheana). Otras expresiones enormemente familiares resuenan en las páginas de este libro, y también en otras obras, notablemente El mito de Sisifo, pero hay que incluir además su narrativa. No faltan, sin embargo, desarrollos personales, como el del nihilismo histórico o en la creación artística, aunque desde luego son también de eco nietzscheano. La honradez de Camus, por su lado es palpable: lo cita más que a ningún otro y en él encuentra el sustrato; la deuda es clara y reconocible. No deja de ser llamativo, en este sentido, que entre la nómina de filósofos que van apareciendo en El hombre rebelde apenas se cita a ningún otro: a Hegel a veces, y ocasionalmente $-y$ como objeto de crítica casi siempre- a Marx. Ni Heidegger, ni Sartre, ni Marcel, ni Jaspers, ni ningún otro de esos que habitualmente se incluyen bajo la etiqueta de existencialistas.

Es, pues, el nihilismo - a lo que Camus llama a menudo "absurdo"- el concepto de intersección con Nietzsche. Pero este término genera abundantes confusiones. Al igual que a Nietzsche, se califica a autores como Camus de nihilistas con un atrevimiento que sólo puede atribuirse a la ignorancia. $Y$ no lo son, pues la concepción del nihilismo en términos de pura negación, esto es, la negación de todo valor, «es ya, en sí misma, un juicio de valor" ${ }^{3}$. El hombre creador asume la vida como pasión, se atreve a enfrentarse a la muerte de Dios o al caos de los valores y reclamar algún orden, sentido. Desde luego, para construir hace falta destruir los viejos santuarios, dice Nietzsche una y otra vez, pero la tarea del filósofo no es sólo dinamitar; fundamentalmente, «el filósofo tiene que solucionar el problema del valor, tiene que determinar la jerarquia de los valoress ${ }^{4}$.

2 Incluso su etapa - y posterior expulsión - en el Partido Comunista es paradigmática de ello, si seguimos la narración que hace de este asunto Herbert LOTTMAN en el capítulo "El partidon de su libro Albert Camus, pp. 175-93.

3 Albert Camus: El hombre rebelde, ed. Alianza, Madrid, 2001, p. 286.

4 La genealogia de la moral, II, ed. Alianza, Madrid, 1981, \$17. 
Camus y los personajes de sus obras dudan, indagan; su circunstancia reclama respuestas, sentido. El no-sentido de las historias y vidas de Meursault, de Calígula, del doctor Rieux, de Kaliayev, reclaman el sentido: buscan con patetismo a veces, otras con desesperación, el orden. Camus no se conforma: no es un nihilista; pide más, pues si la vida es absurda, si todo vale lo mismo (si es relativo), entonces «se puede atizar los hornos crematorios del mismo modo que cabe dedicarse a cuidar leprosos ${ }^{5}$, da igual la solidaridad que el genocidio, Hitler que Teresa de Calcuta, Nerón que Séneca; el verdugo y la víctima son lo mismo desde la moral: algo sin importancia, pues ésta, la moral, carecería de todo fundamento no situacional.

\section{El poder y las formas de violencia}

Hay en toda la obra de Camus una afirmación incuestionable de lo que Nietzsche llamó la inocencia del devenir. Esto es, un anclaje trágico, inevitable, en el más acá. No hay nostalgia de Dios, sino consciencia (dolorosa) de que este mundo es el único existente. Dicho con otras palabras, mirar cara a cara al nihilismo podría conducirnos al narcótico religioso (Nietzsche una vez más) y a su derivación política de búsqueda de lo absoluto en las formas del totalitarismo en nombre, por ejemplo, de Marx. Pero también puede invitarnos a la creación moral. Si el nihilismo deriva en destrucción sin creación, la consecuencia es el estado policial, Hitler, Mussolini, Stalin, lo que llama en El hombre rebelde "teocracias totalitarias del siglo $\mathrm{XX}^{6}{ }^{6}$, esto es, "el terrorismo de Estado" ${ }^{7}$.

Éste es probablemente uno de los núcleos centrales de El hombre rebelde: la denuncia de todo régimen totalitario desde una argumentación basada en la búsqueda de la justicia, lo cual no debió ser en absoluto fácil en el año de su publicación, 1951, cuando lo más popular y sencillo era denunciar los horrores del nazismo y aferrarse al socialismo soviético como una religión salvadora. Como hubiera dicho Nietzsche, cristianos y marxistas participan de lo mismo: la creación ficticia de un mundo utópico alejado de éste (los cristianos, el más allá; los marxistas, el más adelante). Pero cuando queremos que sea la realidad

\footnotetext{
5 El hombre rebelde, op. cit., p. 11.

Ibid., p. 190.

7 Ibid., p. 208.
} 
la que coincida con los deseos, con la teoría, el resultado no puede ser otro que la Historia como expresión e imposición del más fuerte:

"Los individuos en régimen totalitario no son libres, aunque el hombre colectivo sea liberado. Al final, cuando el Imperio libere a la especie entera, reinará la libertad sobre rebaños de esclavos (...). El milagro dialéctico, la transformación de la cantidad en la calidad se aclara aquí: se opta por llamar libertad a la esclavitud total. (...) Si la única esperanza del nihilismo reside en que millones de esclavos puedan constituir, un día, una humanidad libre para siempre, la historia no es más que un sueño desesperadon ${ }^{8}$.

Estamos ante el sueño de la razón, en los dos sentidos que puede darse a la expresión: en primer lugar, como pretensión ilusionante y utópica de liberación que, tras ponerse en marcha, es traicionada y negada (la razón es finalmente derrotada en nombre de la esclavitud que se autodenomina libertad ${ }^{9}$ ), $y$, en segundo lugar, como entrega del logos al sueño, confiando - y renunciando por lo tanto- en que otras instancias (la revolución, la fuerza...) lleven a cabo el trabajo que finalmente terminará con el exterminio de todo atisbo de racionalidad.

Si se repasan los motivos de estas persecuciones en nombre de los elevados ideales que acaban por traicionarse, no sólo aparece de nuevo Nietzsche, sino también Kafka: es la historia del individuo en el que la culpa precede a la explicación, que a menudo ni existe. Se es consciente de la culpa; después, acaso veamos de qué, pero sin duda el castigo es merecido. Nietzsche da un tratamiento religioso al tema por la construcción de las nociones de creación y dependencia, que generan las de deuda, culpa, pecado y mala conciencia. Sin embargo, Camus alude más bien a una cuestión política, aunque desde luego con largas resonancias histórico-literarias:

8 Ibid., p. 272.

9 En La genealogia de la moral, I, $\$ 14$, Nietzsche describe "cómo se fabrican ideales en la tierra", esto es, como desde la voluntad de poder del que domina pueden imponerse denominaciones espurias, pero finalmente aceptadas. Hoy sabemos que puede fabricarse la Historia. En otra obra del pensador alemán, Sobre verdad y mentira en sentido extramoral (ed. Revista Teorema, Valencia, 1980), afirma: "En este mismo momento se fija lo que a partir de entonces ha de ser "verdad", es decir, se ha inventado una designación de las cosas uniformemente válida $y$ obligatoria, y el poder legislativo del lenguaje proporciona también las primeras leyes de verdad, pues aquí se origina por primera vez el contraste entre verdad y mentira" (p. 6). Es la conocida tesis de que la verdad es una mentira social. 
"...un pueblo de culpables caminará sin tregua hacia una imposible inocencia, bajo la mirada amarga de los Grandes Inquisidores" ${ }^{10}$.

En su obra Caligula, hace sostener al emperador romano algo muy similar:

«En función de nuestras necesidades, iremos ejecutando a esos personajes siguiendo un orden arbitrario. Llegado el caso podremos modificar ese orden, siempre de manera arbitraria. (...) Sí, el orden de las ejecuciones carece de la menor importancia. $\mathrm{O}$, mejor dicho, esas ejecuciones tienen idéntica importancia, lo que implica que no la tienen en absoluto. Además, tan culpables son los unos como los otros» ${ }^{11}$.

Podemos imaginar al emperador, a cualquier tirano, buscando culpables para sus purgas. El orden policial exige culpables y víctimas. En un lugar de hombres libres no hay lugar para persecuciones de esta clase. Pero el estado del terror, o el terrorismo de estado, exige víctimas políticas, culpables de traición a la patria, contrarrevolucionarios, enemigos del pueblo y demás palabrería hueca diseñada por cualquier ministerio de propaganda, como enseñan Nietzsche o, más tarde, George Orwell.

Gran parte de El hombre rebelde está dedicado al análisis, crítica y denuncia de todas estas cuestiones, poniendo incluso de relieve analogías de lo que parecían antagonismos. Por ejemplo, pasamos del "opio para el pueblo" con que los marxistas calificaban a la religión, a los enormes paralelismos entre ésta y una doctrina política que acaba por transformarse, para muchos de sus seguidores - fieles - en una suerte de secta con predicciones, mundo demonizado, líderes, doctrina y enemigos. Señala en este sentido Camus que el marxismo ha mezclado «el método crítico más válido con el mesianismo utópico más discutible. Lo malo es que el método crítico, que, por definición, se habría adaptado a la realidad, se halló cada vez más separado de los hechos en la medida en que quiso permanecer fiel a la profecía" ${ }^{12}$. Como es moneda común en las vivencias sectarias, ni el más pertinaz de los hechos altera las predicciones, que, de cientificas ("socialismo cientifico" se ha autodenominado a menudo), han pasado a ser simples profecías que, en una huida hacia adelante, ubican en un futuro improbable. Eso sí, de no darse lo anunciado, el propio sistema genera

10 El hombre rebelde, op. cit., p. 283.

11 Albert Camus: Caligula, ed. Alianza, Madrid, 2001, p. 30.

12 El hombre rebelde, op. cit., p. 221. 
las pertinentes explicaciones ad hoc: no se dan las condiciones, las contradicciones históricas no son suficientes o no lo suficientemente agudizadas, etc. Incluso se llega a introducir la terminología religiosa de la que hablábamos:

"En la medida en que Marx predecía la realización inevitable de la ciudad sin clases, (...), todo retraso en la marcha liberadora debía imputarse a la mala voluntad del hombre. Marx reintrodujo en el mundo descristianizado la culpa y el castigo. El marxismo, bajo uno de sus aspectos, es una doctrina de la culpabilidad tocante al hombre, de inocencia tocante a la historia” ${ }^{13}$.

«Bajo uno de sus aspectos", claro está. Casi es tan innecesario el matiz como reiterar la diferencia entre marxista y marxiano. $\mathrm{Y}$ es bien conocido que toda teoría de liberación, sea religiosa, sea filosófica, encuentra seguidores que la hacen derivar hacia formas de totalitarismo dogmático. No obstante, lo que en religión podría ser aceptable si asumimos una revelación por la divinidad correspondiente o una intuición de lo bueno por el líder «iluminadow, no lo es en el caso de un método que se califica de "crítico" o "científico", y que no admitiría "luces privadas", pues como es bien conocido, aquello que no puede ser falsado, y que en todo hecho o señal encuentra elementos verificadores para sus creencias/hipótesis, será muchas cosas, pero nunca una teoría científico-crítica.

La lectura, por lo tanto, del marxismo en términos religiosos necesariamente lo va a situar en las proximidades de su temática y terminología, y hará brotar conceptos juedo-cristianos como el de culpa, que reaparece con una formulación similar en el marxismo. En ambos casos, al tiempo que se señalan las causas, se remite al castigo, a la pena. En El hombre rebelde, Camus dedica algunas páginas a analizar el fenómeno histórico y moral de los nihilistas rusos del siglo XIX y principios del XX, y que reflejó en otra obra de teatro: Los justos $^{14}$. En ambos textos habla de una especie de "asesinos delicados" o de terroristas con problemas de conciencia, que no son capaces de lanzar una bomba al paso del poderoso si éste va acompañado de niños o de su mujer. Además, estaban dispuestos a pagar con su propia vida ${ }^{15}$, estaban dispuestos a matar y

13 Ibid., p. 280.

14 Albert Camus: Los justos, ed. Alianza-Losada, Madrid, 1982.

15 "Cuando Kaliayev, por ejemplo, decidió en 1903 tomar parte con Savinkov en la acción terrorista, tenía veintiséis años. Dos años más tarde, el "Poeta", como lo llamaban, fue ahorcadon (El hombre rebelde, op. cit., p. 198). 
morir, pero ello en nombre de un valor superior, la justicia en este caso, valor que está igualmente por encima de la propia vida. Por ello, los actos de estos terroristas apuntan nuevamente al futuro, al tiempo de la promisión, que ellos se encargan - creen - de acercar a lo real, sin que importe si formarán parte de dicha realidad: son instrumentos de la historia, profetas y catalizadores del porvenir. Precisamente esto es lo que libra a los terroristas, a todo terrorista, del sentimiento de culpa, de la mala conciencia:

«El que mata o tortura sólo conoce una sombra en su victoria: no puede sentirse inocente. Necesita, pues, crear la culpabilidad en la víctima misma para que, en un mundo sin dirección, la culpabilidad general no legitime más que el ejercicio de la fuerza, no consagre más que el éxito" ${ }^{16}$.

Parece que el estudio que hace Camus del terrorismo está escrito para el mundo de hoy, pero no para anticiparlo, sino para enfrentarnos a él aún con más criterios. Una de las características más perversas de nuestros terroristas domésticos es la transmutación del lenguaje que convierte a las víctimas en verdugos y a los verdugos en víctimas, a los enemigos de la democracia en los principales usuarios de esa palabra, a su grupo organizado de asesinos en un producto inevitable del contencioso. Pero, además, la principal diferencia es que éstos terroristas no son en absoluto "asesinos delicados", ni tampoco están dispuestos, como ellos a la autoinmolación en nombre de la justicia. No; actúan de lejos y a cubierto, aprovechan los beneficios de los estados que dicen combatir (financiación de partidos afines, derechos penitenciarios...) y carecen de cualquier prejuicio de orden moral. Su lógica es la de la guerra, no la de la justicia. Sólo les asemeja a los terroristas rusos de los que habla Camus su desplazamiento de la culpa. Si ésta es expulsada hacia la víctima, que es de este modo susceptible de ser sometida a pena (esto es, "arrestado", «ejecutado", etc.), el remordimiento no tiene lugar ${ }^{17}$.

En efecto, los nihilistas/terroristas rusos acallan las preguntas sobre su legitimidad con la disposición a perder su propia vida, con la que hacen

16 El hombre rebelde, op. cit., p. 216.

17 Nuevamente encontramos en Nietzsche claves al respecto. En La genealogia de la moral, II, especialmente en el parágrafo 16, desarrolla el autor alemán esta cuestión: lo que no puede manifestarse hacia fuera se interioriza, ése es el origen de la mala conciencia, el instinto de crueldad vuelto hacia dentro. 
frente a la eventual autoculpabilización. Por ello, eran seres «solitarios con su desesperación, frente a sus contradicciones que no podían solucionar más que con el doble sacrificio de su inocencia y de su vida" ${ }^{18}$. Por el contrario, los que vengan después, esa otra clase de terroristas contemporáneos, si bien aceptan algún riesgo, es sólo el mínimo preciso: el presente les importa más, el valor prometido no se aplaza ni debe ir más allá de la vida del que tire la bomba. En este sentido no puede hablarse con propiedad de nihilismo, pues el propio Camus reconocía que «no hay pensamiento absolutamente nihilista, sino, quizás, en el suicidio" ${ }^{19}$. Y, desde luego, no puede interpretarse como suicidio más o menos consentido la disposición al castigo con que los terroristas rusos emprendían sus crímenes. No pueden identificarse como esa otra variante actual: el "terrorista suicida". Una cosa es estar dispuesto a asumir el riesgo y otra ofrecer la vida propia por la causa.

Si nos detenemos unas líneas en esta cuestión, veremos que se viene abajo otro de los falsos tópicos pensamiento camusiano que convertiría al francés en un apologeta del suicidio. Recordemos unas palabras suyas muy conocidas:

"No hay más que un problema filosófico verdaderamente serio: el suicidio. Juzgar si la vida vale o no vale la pena de vivirla es responder a la pregunta fundamental de la filosofía. Las demás, si el mundo tiene tres dimensiones, si el espíritu tiene nueve o doce categorías, vienen a continuación" ${ }^{20}$.

Pero señalar al suicidio como el problema más importante de la filosofía no indica que la muerte sea el objeto central de su pensamiento. El suicidio nos hace preguntarnos si vale o no la pena vivir (en la misma expresión encontramos una concepción de la vida como castigo o penitencia); es decir, el suicidio nos remite a cuestionarnos el valor de la vida: éste el corazón de la filosofía. La consciencia de la muerte nos lleva a la pregunta por la vida y la renuncia voluntaria a ésta, la abdicación de la existencia, anula todo mal-estar, pero también toda lucha, toda rebeldía. En ese sentido, si recuperamos el comienzo de $E l$ hombre rebelde, nos encontramos con la siguiente argumentación:

18 El hombre rebelde, op. cit., p. 195.

19 Ibid., p. 287.

20 Albert Camus: El mito de Stsifo, ed. Alianza-Losada, Madrid, 1983, p. 15. 
"La conclusión final del razonamiento del absurdo es, en efecto, el rechazo del suicidio y el mantenimiento de esa confrontación desesperada entre la interrogación humana y el silencio del mundo" ${ }^{21}$.

Es más, en la página siguiente define el nihilismo absoluto como «aquel que admite legitimar el suicidion. En este sentido, el suicidio representaría el final de la tensión entre el hombre que interroga y el silencio que (no) responde, las paradojas del absurdo, el vacío existencial. Pero su ejecución es contradictoria porque elimina la vida, que es precisamente la condición de la confrontación del hombre con el absurdo. Creo que éste es justamente el mensaje que Camus pretendía transmitir en El mito de Sísifo.

Terminaré esté punto con la constatación de que, frente a los tópicos del existencialismo (admitamos por un momento la inserción de Camus en este movimiento, aunque sólo sea en un sentido muy laxo), la totalidad de El hombre rebelde está consagrada a problemas de tipo social. El mismo título lo sugiere, y el comienzo de la obra lo explicita largamente: el hombre rebelde lo es frente a algo, frente a la esclavitud, la injusticia, frente a los amos y los negadores de cualquier especie de libertad:

«... el esclavo se subleva por todas las existencias a un tiempo cuando juzga que, bajo este orden, se le niega algo que no le pertenece únicamente a él, sino que es un ámbito común en el que todos los hombres, incluso el que lo insulta y lo oprime, tienen dispuesta una comunidad ${ }^{22}$.

No todo, pues, es individualismo. Muy al contrario, justicia y libertad no son valores del hombre solitario, sino del ser social. Un poco más adelante lo reafirma:

"La solidaridad de los hombres se funda en el movimiento de rebeldía, y éste, a su vez, sólo halla justificación en esta complicidad. Tendremos, pues, derecho a decir que toda rebeldía que se autoriza a negar o a destruir esta solidaridad pierde al mismo tiempo el nombre de rebeldía y coincide en realidad con un consentimiento criminal" ${ }^{23}$.

21 Op. cit., p. 12.

22 Ibid., p. 24.

23 Ibid., p. 31. 
Llama la atención la claridad y rotundidad de estas palabras. Si ha podido parecer alguna vez, incluso en otras obras (pienso especialmente en Los justos), que en la filosofía de Camus hay algún tipo de justificación del terrorismo, califíquese a los terroristas con dicho nombre o con otros como «asesinos delicados", no hay como leer estas líneas para reflexionar sobre la errónea lectura. El rebelde se asemejaría más al desobediente civil que al terrorista (en el sentido actual de estas palabras). Al rebelde le importa el futuro, le importa la justicia, incluso vive en medio de grandes contradicciones morales, pero es un ser que quiere la justicia y la libertad con los demás y no sin ellos, mucho menos a pesar de ellos. El desobediente civil, al igual que el rebelde, no se esconde, es más, pide su castigo, pero no porque se reconozca culpable, sino como procedimiento de pública denuncia. Su culpabilidad es legal, no legítima, no moral.

Esto nos remite a un nuevo problema que apenas voy a esbozar: si el ser humano actúa en sociedad, si libertad y justicia son virtudes sociales, entonces, dice Camus, cabe "la sospecha de que hay una naturaleza humana" ${ }^{24}$. Éste es un punto que le separaría de Sartre, con su negación radical de dicha naturaleza humana. Sostenía este último lo siguiente:

«...no puedo contar con hombres que no conozco fundándome en la bondad humana, o en el interés del hombre por el bien de la sociedad, dado que el hombre es libre y que no hay ninguna naturaleza humana en que pueda yo fundarme" 25 .

No obstante, partamos de la naturaleza humana o de la convicción de que actuamos sin ella, lo común en estos pensadores es que la importancia de la filosofía no es especulativa sino práctica. Si utilizamos las palabras que Cesonia, la amante y confidente de Calígula, sostiene en discusión con él, podríamos conjeturar con ella que «existe lo bueno y lo malo, lo alto y lo bajo, lo justo y lo injusto" ${ }^{26}$. Esta cuestión es central en la historia de la ética, y nos conduciría desde la afirmación del Bien y las ideas morales en Platón hasta las formas de relativismo o emotivismo actuales, tan extendidas y populares por

24 Ibid., p. 24.

25 Jean-Paul SARTRE: El existencialismo es un humanismo, ed. del 80, Buenos Aires, 1981, p. 27.

26 Calígula, op. cit., p. 38. 
(falsamente) democráticas ${ }^{27}$. Pero esta preexistencia de los valores morales no parece sostenerla de modo tan explícito Camus; desde luego, sería negada por Sartre ${ }^{28} \mathrm{y}$, por supuesto, por Nietzsche. Camus se acercaría más, como veremos después, a lo que hoy se llama "moral mínima" y que en El hombre rebelde su autor denomina "necesidad del límite».

\section{Los valores: Dios, vida, libertad}

Si retomamos el hilo del punto anterior, constataremos que, en la comparación con Sartre respecto al tema de los valores, es donde vamos a hallar más diferencias. En efecto, el existencialismo sartreano parte de la subjetividad: el hombre debe crear, pero no hay criterios absolutos. En esto se asemeja mucho a Nietzsche y su perspectivismo, pues, según el alemán, "no existen fenómenos morales, sino sólo una interpretación moral de fenómenos" ${ }^{29}$. Camus, por el contrario, está más cerca de concepciones contemporáneas como las de Apel y Habermas. Veremos que hay algunas similitudes entre la reivindicación que hace Camus de la "filosofía del límite" y eso que se ha dado en llamar recientemente «ética mínima», «mínimos de justicia» o "éticas dialógicas». Estas posturas no asumen la existencia de valores máximos absolutos, al modo de las ideas platónicas, por lo que, si nuestra tesis es correcta, no estaría Camus exactamente en la línea filosófica representada por las palabras de Cesonia antes

27 El común de los hombres cree que es ser muy democrático afirmar que toda opinión es respetable. Pero no: son las personas lo respetable, no sus opiniones, y una democracia que merezca ese nombre incluye el respeto a los ciudadanos y el derecho a discutir con argumentos y rechazar, si es el caso, sus opiniones, que no necesariamente son respetables ni verdaderas. Lo que tenemos, si aceptamos sin reflexión que "todo es respetable", es un mosaico de palabras y modos de vida incomunicables $y$, lo que es peor, algunas de las cuales se empeñan en imponerse a los demás, por la fuerza si es preciso.

28 «El existencialista, por el contrario, piensa que es muy incómodo que Dios no exista, porque con él desaparece toda posibilidad de encontrar valores en un cielo inteligible; ya no se puede tener el bien a priori, porque no hay más conciencia infinita para pensarlo; no está escrito en ninguna parte que el bien exista, que haya que ser honrado, que no haya que mentir; puesto que precisamente estamos en un plano donde solamente hay hombres" (El existencialismo es un humanismo, op. cit., p. 21).

29 Friedrich NIETZSCHE: Más allá del bien y del mal, ed. Alianza-Orbis, Barcelona, 1983, $\$ 108$. Y en el prólogo del mismo libro afirma: «En todo caso, hablar del espiritu y del bien como hizo Platón significaría poner la verdad cabeza abajo y negar el perspectivismo, el cual es condición fundamental de toda vida» (p. 19). 
citadas -cuando mantiene la existencia de los valores morales y la demarcación entre lo bueno y lo malo-, pero tampoco junto al relativismo de Calígula o la indiferencia de Meursault.

La inadecuación ser/deber ser (falacia naturalista al margen) es el germen de toda filosofía transformadora. Naturalmente, el ser forma parte de la inocencia del mundo, que diría Nietzsche, pero el deber ser es un añadido, una exigencia moral que no está en modo alguno en lo real, sino en nuestra apreciación de ello. Frente a la preexistencia de los valores, su negación o su destrucción en nombre del nihilismo, Camus propone «una filosofía del límite», la creación de un sistema de convivencia y libertades para todos, la delimitación de tales libertades a partir de mínimos de justicia. Desde luego, una justicia humana mínima sin fundamento religioso, aunque con posibles desarrollos vitales de esta índole, pero que excluya un relativismo que sólo es ventajoso para el que manda:

«El hombre en rebeldía es el hombre situado antes o después de lo sagrado, y dedicado a reivindicar un orden humano en el que todas las respuestas sean humanas" ${ }^{30}$.

Podríamos decir incluso que la dialéctica amo/esclavo es una modalidad de la relación divinidad/ser humano. El problema, reelaborado al modo del vitalismo nietzscheano, sería el papel de Dios (del Dios judeo-cristiano) en el fundamento de la moral. La muerte de Dios (también Dostoievski, Sartre...), aunque no es reclamada por Camus con la vehemencia de los autores antes citados, sí es tratada en El hombre rebelde, por ejemplo al citar al escritor ruso:

"Como Dios y la inmortalidad no existen, le está permitido al hombre nuevo ${ }^{31}$ convertirse en Dios" ${ }^{32}$.

Camus constata que uel reino de la gracia ha sido vencido, pero el de la justicia se desploma también» ${ }^{33}$. La sustitución de Dios, tan querida por el grupo

30 El hombre rebelde, op. cit., p. 30.

31 El Superhombre (Úbermensch) de Nietzsche es justamente esta idea de ser humano de la que habla aquí el autor ruso y reproduce Camus, y no la supuesta raza superior con la que los nazis pretendieron rellenar la palabra.

32 Op. cit., p. 75.

33 Ibid., p. 326. 
vitalista/existencialista no se ha producido, pero sí el hundimiento de la moral con el de su valedor. Parafraseando a Dostoievski/Sartre, podríamos decir que, si Dios ha muerto, los valores no existen. Al fin y al cabo, la lógica de la ausencia de Dios puede conducir tanto al nihilismo de la destrucción como al de la creación. O, como dice un personaje de Los justos, "para los que no creemos en Dios, o tenemos toda la justicia, o la desesperación” ${ }^{34}$.

Camus parte del nihilismo resultante de la muerte de Dios, pero para proponer, para construir. No es aceptable que con la gracia se desplome también la justicia. Por ello, el hombre rebelde no dice exactamente no, sino algo más; en realidad busca el sí. El hombre rebelde sabe del absurdo, habita en él, en su paradoja. El absurdo, Camus lo sabe, «en sí mismo es contradicción" ${ }^{35}$. Pero al igual que han mostrado otros filosofos en sentidos similares (Kant, Wittgenstein...), frente a lo que no es susceptible de ciencia o de lenguaje, la alternativa del silencio o del no-sentido es una opción, pero no la mejor opción. Si lo racional (en el sentido científico-técnico de la palabra) no es predicable de la acción moral, lo mejor no es lo irracional, sino lo razonable. Con desiguales puntos de llegada, tanto Kant como Wittgenstein sitúan en el corazón de sus preocupaciones a la ética. Si en la vida no podemos dejar de actuar, pues no elegir es también hacerlo, si ante lo ineludible de la acción sólo nos queda el silencio a la hora de su valoración, como el filósofo vienés pretendía, entonces, como a él, sólo nos queda la nostalgia de que se pudiera decir algo sobre los problemas morales. El filósofo de Königsberg, más próximo a Wittgenstein de lo que suele decirse, empleó sus esfuerzos en la delimitación del ámbito práctico, esto es, de lo pensable. La existencia de la ley moral es tan necesaria (otra cosa es que sus leyes sean necesarias) como la ley científica, más aún, pues contiene los grandes problemas del ser humano.

Pues bien, todas estas apelaciones a la historia de la filosofía vienen a decir que el problema no es nuevo. No son tratadas por Camus, pero se hallan al fondo de su argumentación y de su posicionamiento frente al perspectivismo y relativismo. Camus se alinearía aquí más con Kant que con Nietzsche. Pero les añadiría una dimensión colectiva que no está en ellos o no es tan central. Respecto a este salto a lo social, afirma Camus:

34 Op. cit., p. 60.

35 El hombre rebelde, op. cit., p. 15. 
«En la experiencia del absurdo, el sufrimiento es individual. A partir del movimiento de la rebeldía, cobra conciencia de ser colectivo, es la aventura de todos" ${ }^{36}$.

Ya sabemos que Camus insiste una y otra vez en que su análisis es desde la justicia, precisando muy bien los límites que evitarían el crimen en nombre de la justicia social, como se ha hecho también en nombre de Dios. Por eso insiste en que la libertad inicia la revolución, pero la "justicia" acaba por abolirla ${ }^{37}$. Hablamos, claro, de «justicia» en un sentido ideologizado y rígido, una suerte de "lealtad inquebrantable", de tal modo que el mundo social debe acomodarse al concepto y no al contrario. Camus, en el mismo lugar antes reseñado, califica a estas revoluciones de "rebeldías serviles". No son el lugar donde habita el hombre rebelde. Para explicarlo mejor recurriremos a dos textos sacados de las últimas páginas del ensayo que comentamos:

«La rebeldía no es en modo alguno una reivindicación de libertad total. (...) Discute precisamente el poder ilimitado que autoriza a un superior a violar la frontera prohibida" ${ }^{38}$.

"La libertad absoluta es el derecho para el más fuerte a dominar. Mantiene, pues, los conflictos que benefician a la injusticia. La justicia absoluta pasa por la supresión de toda contradicción: destruye la libertad. La revolución para la justicia, por la libertad, acaba enfrentándolas una con otra" ${ }^{39}$.

Aunque pueda parecer paradójico, la propuesta de Camus no es la de la libertad absoluta («siempre se es libre a expensas de otro», dice Calígula ${ }^{40}$ ), sino una libertad para todos, lo cual hace preciso algún tipo de límite. Pero debemos entender bien ese concepto. El límite es orden y justicia. No es falta de libertad, sino su condición.

En dos obras dramáticas se reproduce una discusión similar: en Calígula, el emperador manifiesta que «a partir de hoy y en lo sucesivo, mi libertad dejará

\footnotetext{
36 Ibid., p. 31.

37 Ibid., p. 129.

38 Ibid., p. 330.

39 Ibid., p. 334

40 Caligula, op. cit., p. 64.
} 
de tener límites" ${ }^{41}$, mientras que otro personaje califica de "delirio de un loco" a ese juego "que no tiene límites» ${ }^{42}$. En Los justos, la disputa entre Dora y Stepan contiene los mismos elementos: Dora argumenta que "hasta en la destrucción hay un orden, hay límites», mientras que Stepan le responde violentamente que uno hay límites. La verdad es que vosotros no creéis en la revolución" ${ }^{43}$. Camus proclama, por lo tanto, poniéndolo en boca de alguno de sus personajes, la necesidad del límite. De lo contrario, podríamos asentir a la afirmación de Kaliayev en la discusión anterior cuando replica a Stepan que «detrás de lo que dices veo anunciarse un despotismo que, si alguna vez se instala, hará de mi un asesino cuando trato de ser un justiciero" ${ }^{44}$.

Por ello, frente a lecturas tan alejadas de la vida y obra de Camus, el propio autor se encarga de dejar claro que el hombre rebelde no dice no más que como un paso para decir sí, esto es, para crear o recuperar la justicia. El hombre rebelde no destruye más que para construir lo nuevo o de nuevo. Lo reitera con las siguientes palabras:

"La mesura no es lo contrario que la rebeldía. Es la rebeldía la que es la mesura, la que la ordena, la defiende y la crea de nuevo a través de la historia y sus desórdenes» ${ }^{45}$.

Al ccmienzo de este punto sugeríamos la proximidad de Camus a escuelas y conceptos más actuales como los mantenidos por la Escuela de Francfort sobre esos mínimos de justicia. Cuando los francfortianos hablan de «universalismo dialógico", por ejemplo, están hablando de unas condiciones de racionalidad comunicativa que hacen posible la convivencia y los proyectos particulares de vida feliz. Estas condiciones serían pragmáticas, trascendentales, a menudo contrafácticas. Pues bien, creo que la cita antes expuesta de Camus está en la misma línea. Límite no quiere decir en modo alguno menoscabo de libertades o derechos fundamentales, sino aspiración a unos mínimos de convivencia universal. La "restricción" de la libertad, cuando habla de ella (alguna vez con cierta imprecisión que podría inducir a malinterpretar), no lo es en

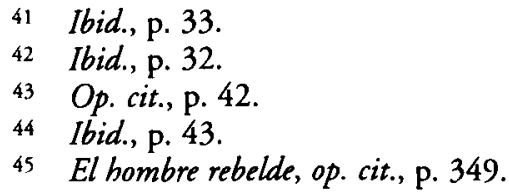


nombre de otra cosa que la evitación del sufrimiento y la extensión de la justicia. Por ello estaría tan lejos de esa libertad que reclama Calígula en la obra del mismo título, que no es otra cosa que aspiración a la omnipotencia, lo cual deriva en el dominio absoluto. Y quien posee tales privilegios ¿va a ocuparse de la justicia y libertad para todos? El límite del que habla Camus es precisamente su antítesis: la justicia es la condición de posibilidad de la libertad. Si la libertad absoluta gana la batalla, estaremos ante la libertad de los poderosos, que no de los mejores. La justicia habrá perdido: retornará la peste con sus múltiples rostros. El doctor Rieux, Camus, lo saben.

\section{Conclusiones: del nihilismo al sentido}

En primer lugar, reitero los avisos iniciales: la lectura de El hombre rebelde es nietzscheana. No fielmente, no sectariamente. Como el propio libro, claro. Por eso, en el subtítulo del artículo se dice "lectura casi nietzscheana". El principal reproche que Camus haría a Nietzsche es el de su perspectivismo, incluso el de su aristocratismo. En este sentido, en el capítulo dedicado al pensador alemán afirma lo siguiente:

«El caos también es una servidumbre (...). Sin ley no hay libertad. Si el destino no está orientado por un valor superior, si el azar es rey, el resultado es la marcha entre las tinieblas, la espantosa libertad del ciegon" ${ }^{46}$.

En estas tesis no late precisamente el espíritu de Nietzsche, sino al contrario: se hallan en la línea de la hipótesis apuntada con anterioridad, esto es, si nada es verdad, entonces todo esta permitido; pero que todo esté permitido no significa en modo alguno que todo valga lo mismo. Ésta es, seguramente, la diferencia más importante con Nietzsche (también con Sartre). Camus participa de la visión de Dioniso como belleza que ama la vida, con lo que ella conlleva: el gozo y el dolor. Camus es un vitalista, sin duda, como Nietzsche. A veces comparte con Sartre temática, incluso algunos elementos filosóficos de ambos son intercambiables. Sin embargo, los matices son precisos. Así, cuando el existencialismo sartreano define la vida como pasión inútil, Camus podría compartirlo, pero precisando que pasión es el sustantivo, lo sustantivo.

46 El hombre rebelde, op. cit., p. 89. 
Que sea inútil o no es otra cuestión: lo será en el más allá, pero no es indiferente que lo sea aquí. Por ello, porque en esta filosofía no hay resignación, no puede hablarse de un pensamiento de la tristeza o la desesperación: crear, buscar, es apostar por la alegría de la vida, incluso donde la creación es la única alegría posible. Al respecto, decía Camus:

"... los hombres de mi generación han visto demasiadas cosas para imaginar que el mundo de hoy pueda parecerse a una biblioteca de novelas rosa. Saben que existen las cárceles y las ejecuciones al amanecer; saben que a veces se mata la inocencia y puede triunfar la mentira. Pero eso no es desesperación. Eso es lucidez. ¡La verdadera desesperación es totalmente ciega! La verdadera desesperación es la que consiente el odio, la violencia y el crimen. Yo nunca he cedido a ese tipo de desesperación» ${ }^{47}$.

En el mismo sentido, en un artículo publicado en con motivo del 80 aniversario del nacimiento de Albert Camus, Fernando Savater afirmaba lo siguiente sobre el autor francés:

«... le recordamos lo suficientemente bien como para saber que no defendió crímenes, ni justificó masacres, ni se regodeó en el elogio político o estético (¡Sade!) de ninguna forma de crueldad. No padeció la cobardía física que suele empujar a los intelectuales al elogio de la violencia e incluso a lo que Chesterton justamente llamó "el menos viril de los vicios": la fascinación por la brutalidad. (...) Tampoco se equivocó en su denuncia de la pena de muerte y del terrorismo, extremos simétricos de la inmolación del individuo a la razón de Estado" ${ }^{48}$.

Como puede observarse, aunque el punto de partida es el mismo que en Nietzsche, el punto de llegada es sólo similar. Como el alemán, Camus constata que "no son la rebeldía ni su nobleza las que brillan hoy sobre el mundo, sino el nihilismo" ${ }^{49}$. Por eso hay que ir más allá; por eso ni Camus ni Nietzsche son nihilistas, sino notarios y hasta debeladores del nihilismo, pues no basta con mostrar las sombras que se ciernen sobre Europa: hay que pro-

47 Fragmento de una entrevista en Radio Argel, realizada por Emmanuel RoBLES en noviembre de 1947; recogido por el mismo autor en su libro: Camus, hermano de sol, ed. Alfons el Magnànim-IVEI, Valencia, 1995, pp. 108-9.

48 "Más nuestro que nunca", Babelia. Revista de cultura, N. $107,30 . X .93$, p. 4.

49 El hombre rebelde, op. cit., p. 123. 
poner mensajes positivos para no instalarse en la inacción moral. A veces se evoca a Meursault, pero Camus es, a mi juicio, aún más el doctor Rieux de La peste. La enfermedad está ahí, pero su diagnóstico no basta: hay que vencerla, al menos dar la batalla ${ }^{50}$. Al fin y al cabo, "no es la rebeldía en sí misma la que es noble, sino lo que exige" 51 .

Podríamos concluir esta cuestión con las siguientes palabras:

"Hay que construir entonces el único reino que se opone al de la gracia, el de la justicia, y reunir por último la comunidad humana sobre las ruinas de la comunidad divina" 52 .

Esta cita posee un inequívoco tono nietzscheano, y es casi una paráfrasis de esta otra del autor alemán:

"Para poder levantar un santuario hay que destruir un santuario: ésta es la ley. (...) ese anticristo y antinihilista, ese vencedor de Dios y de la nada alguna vez tiene que llegar.... 53 .

Los ejemplos podrían alargarse hasta el infinito. En las últimas páginas de $E l$ hombre rebelde, Camus sostiene bajo el mismo espíritu nietzscheano lo siguiente:

"Más allá del nihilismo, todos nosotros, entre las ruinas, preparamos un renacer, pero pocos los saben" ${ }^{54}$.

Está contenido aquí el aristocratismo, Zaratustra, el Superhombre, el hombre del futuro, como queramos llamarlo. No es exactamente mesianismo, como a veces se dice de Nietzsche, pero tal vez sí exista aquí un ápice de lo que Camus reprocha al cristianismo y a los regímenes del marxismo real: su apuesta o esperanza en el futuro (el más allá o la historia). En cualquier caso, y no

so No es necesario recordar todos los movimientos en que se involucró Camus, desde su apoyo a la República Española hasta su implicación personal en el conflicto surgido con la independencia de Argelia, su rechazo a la invasión soviética de Hungría, etc. En la biografía de Lottman hay detalladas narraciones de todos estos compromisos, entre otros. Igualmente puede consultarse el libro de Olivier TopD: Albert Camus. Una vida, ed. Tusquets, Barcelona, 1997.

51 El hombre rebelde, op. cit., p. 123.

52 El hombre rebelde, op. cit., p. 124.

53 La genealogia de la moral, II, op. cit., $\$ 24$.

54 Op. cit., p. 354. 
es coincidente aquí con el filósofo alemán, en Camus la justicia es la brújula que orienta el análisis de todo lo demás. Dicho término es aún más importante en él que el de libertad. Frente a Nietzsche, el perspectivista Nietzsche, Camus es un buscador de la justicia. Frente a Sartre, al que se califica a menudo como "filósofo de la libertad», Camus hace más hincapié en la justicia. Desde luego, ambos conceptos no son disociables: no hay humanidad digna sin ambas, pero no son lo mismo. La justicia, en Camus, es la condición de la libertad, de la libertad genuina, claro, no de la libertad arbitraria y omnipotente, no la libertad de cualquier régimen que, en su nombre, acaba por despreciar la justicia.

Para terminar, sería pertinente recoger un texto que resumiese e hiciese confluir todo lo anterior:

"Cabe decir, pues, que la rebeldía, cuando desemboca en la destrucción, es ilógica. Reclamando la unidad de la condición humana, es fuerza de vida, no de muerte. Su lógica profunda no es la de la destrucción; es la de la creación" 55 .

¿Nos queda, en definitiva, la falta de sentido o la esperanza de que los valores existan? Carecer de la firmeza de las ideas platónicas o de los asideros de la fe no parece suficiente razón para echarse a un lado. Por ello, aunque sin el lenguaje más contemporáneo de los francfortianos, Camus reclama una moral mínima, unos mínimos de justicia. Si Dios no existe, si no hay fundamento más sólido que la intersubjetividad humana (¿la uunidad de la condición humana» sería el equivalente en el escritor francés?), entonces hay que imaginarse al autor francés como el Sísifo que describe. Muy cerca de él, Camus vive con dramatismo pero con dicha la vida y sus compromisos sin recompensa final, ni en el más allá de la religión, ni en el más tarde de la historia. «No hay castigo más terrible que el trabajo inútil y sin esperanza" ${ }^{56}$, pero esto es la vida y la búsqueda de la justicia. La roca que Sísifo (Camus) sube a la cima de la montaña vuelve a caer. "Sísifo es el héroe absurdo" ${ }^{57}$, sin esperanza pero no desesperanzado. No obstante, Sísifo (Camus) emprende su tarea con alegría: «Su destino le pertenece. Su roca es su cosa» ${ }^{8}$.

\footnotetext{
$55 \quad$ Ibid., p. 331.

56 El mito de Sisifo, op. cit., p. 157.

57 Ibid., p. 158.

58 Ibid., p. 161.
} 